\title{
Interação de um Aluno com Paralisia Cerebral com Colegas de Classe Durante Atividades Ludicas ${ }^{1}$ \\ Interaction of a Student With Cerebral PaLsy With Classmates During PLAY ACTIVITIES
}

\author{
Adriane Guzman PASCULLI² \\ Luciana Ramos BALEOTTI ${ }^{3}$ \\ Sadao OMOTE ${ }^{4}$
}

\begin{abstract}
RESUMO: objetivou-se verificar a qualidade das relaçóes interpessoais que se estabelecem entre uma criança com paralisia cerebral (PC) e seus colegas de classe durante atividades lúdicas em grupo realizadas em sala de aula e durante o recreio. Participaram deste estudo uma criança com diagnóstico clínico de PC quadriplégica, o professor e seus colegas de classe. A coleta de dados deu-se por meio de um roteiro de entrevista aplicado ao professor e por filmagens da criança com PC em atividades lúdicas com seus colegas. A análise de dados da entrevista foi feita de forma qualitativa e a análise da filmagem por meio de um sistema de categorias. Os resultados evidenciam que a professora tem a percepçáo de que a criança com PC tem interesse e participa de atividades lúdicas e interage satisfatoriamente não somente com parceiros habituais, mas com todos os colegas de classe. Por outro lado, a análise das filmagens evidencia que de fato a interação ocorre positivamente, porém a criança com PC permanece a maior parte do tempo mais como observadora das atividades do que como participante ativa, possivelmente em funçấo da lacuna entre as possibilidades dessa criança e as demandas das atividades desenvolvidas no contexto escolar.
\end{abstract}

PALAVRAS-CHAVE: Educação Especial. Paralisia Cerebral. Interação Social. Participação do aluno.

\begin{abstract}
The study aimed to examine the quality of interpersonal relationships developed between a child with cerebral palsy (CP) and his classmates during group play activities carried out in the classroom and during recess. The participants of the study were a boy with clinical diagnosis of quadriplegic CP, his teacher and classmates. Data collection was carried out by means of a structured interview with the teacher and of video recording the child with CP interacting with his classmates in play activities. The interview data analysis was carried out using qualitative procedures and the video recording was analyzed using a category system. The results showed that the teacher perceived the child with CP to be interested; he participated in play activities and interacted successfully both with familiar partners and with all classmates in general. On the other hand, the analysis of the video recorded activities showed that even though interaction did in fact occur positively, the child with CP remained mostly an observer of the activities rather than an active participant, possibly due to the gap between the child's possibilities and the requirements imposed by the activities underway in the school setting.
\end{abstract}

KEYWORDS: Special Education. Cerebral Palsy. Social Interaction. Student participation.

\section{INTRODUÇÁO}

A paralisia cerebral (PC) é uma disfunção predominantemente motora que torna o movimento voluntário descoordenado, estereotipado e limitado, podendo ou não estar associada a distúrbios cognitivos, visuais, auditivos, de atenção e comportamentais (MILLER; CLARCK, 2002).

\footnotetext{
${ }^{1}$ Este estudo contou com o apoio da Fapesp - Fundação de Amparo à Pesquisa do Estado de Sáo Paulo. (Processo 2009/08036-9)

${ }^{2}$ Terapeuta Ocupacional graduada pela Universidade Estadual Paulista, Faculdade de Filosofia e Ciências, Unesp, campus de Marília. Especialização em Intervençóes em Neuropediatria, Universidade Federal de São Carlos, Ufscar. dripasculli@yahoo.com.br

${ }^{3}$ Professora Assistente Doutora. Departamento de Fisioterapia e Terapia Ocupacional. Faculdade de Filosofia e Ciências, Unesp, campus de Marília. baleotti@marilia.unesp.br

${ }^{4}$ Docente do Departamento de Educação Especial e do Programa de Pós-Graduação em Educação, UNESP, campus de Marília. somote@uol.com.br
} 
Os efeitos da limitação capacitante na criança com PC podem refletir em seu poder de vivenciar, através da brincadeira, a criatividade, o conhecimento de regras, as socializações, as perdas e os ganhos, vivências essas que têm efeito sobre o seu desenvolvimento. Através do brincar, a criança experimenta novos desafios, soluciona problemas e é capaz de executar funçóes. Brincando a criança aprende e amplia sua capacidade de adaptação, autonomia e interação com os outros (ARAÚJO; GALVÃO, 2007).

As brincadeiras e os jogos são muito utilizados como recurso de ensino principalmente na Educação Infantil e nas séries iniciais do Ensino Fundamental. Utilizar a brincadeira como recurso no processo de ensino é aproveitar a motivação interna que as crianças têm para tal comportamento e tornar mais atraente a aprendizagem de conteúdos escolares, além de favorecer a interação entre elas (CORDAZZO; VIEIRA, 2007).

Por meio do lúdico, a criança interage com o mundo, favorecendo a iniciativa, a autoconfiança e a autonomia, fatores significativos para a aprendizagem (JULIANI; PAINI, [2008]). O brincar proporciona também sua interação social com outras crianças da família, amigos, colegas da escola e vizinhança, e com estes adquire habilidades que não seria capaz de aprender sozinha (SILVA; CABRAL; CHRISTOFFEL, 2008).

Considerando que a atividade lúdica pode proporcionar a todas as crianças a vivência de situaçóes ricas de interação social, favorecê-la nos diferentes contextos sociais nos quais a criança com PC está inserida é extremamente importante. Enfatiza-se a escola como um dos principais ambientes onde as crianças interagem com seus pares.

Para Andretto (2001), a escola, por promover interaçóes, exerce uma importante função social. As interaçóes podem produzir efeitos significativos na vida dos alunos, promovendo desenvolvimento e aprendizagem, além de dar oportunidade de as crianças aprenderem umas com as outras e desenvolverem atitudes, habilidades e valores necessários para a vida em comunidade.

$\mathrm{Na}$ escola, o professor e os colegas de sala são os principais interlocutores com os quais o aluno com PC pode interagir. Para favorecer a interação social, há a necessidade de que os professores estruturem situaçóes que estimulem e favoreçam a cooperação entre os envolvidos e permitam construir conhecimentos por parte de todos os alunos, inclusive do aluno com deficiência. O trabalho didático deve ocorrer no sentido de criar um adequado ambiente interacional e educativo (BALEOTTI, 2006).

A escola é o lugar onde existem oportunidades de convivência de crianças da mesma idade, que possuem interesses comuns, conhecimentos e necessidades que podem ser compartilhados por estarem na mesma situação. Assim, a interação social entre alunos com e sem necessidades educacionais especiais permite trocas sociais e pode ampliar as capacidades individuais (PIMENTEL, 2006). As relações de amizade dentro do contexto escolar são relevantes para o desenvolvimento da aprendizagem e aquisição de habilidades sociais (LOPES; MAGALHÁES; MAURO, 2003).

Esta interpretação é coerente com os resultados de alguns estudos realizados na área, que objetivaram analisar a interação social de crianças com as mais diversas deficiências inseridas em escolas regulares. Ao relacionar o processo de interação social com a inclusão de 
crianças com síndrome de Down na Educação Infantil, constata-se que para essas crianças, ao ingressarem na escola, a relação interpessoal com os colegas abre-lhes uma maior variabilidade de modelos e demandas para a aquisição de novas habilidades sociais (ANHÃO; PFEIFER; SANTOS, 2010). O mesmo acontece com as crianças com Síndrome de Down inseridas no Ensino Fundamental. Os resultados de um estudo realizado por Teixeira e Kubo (2008) apontam que as crianças que participavam das atividades de aula juntamente com seus colegas de classe tinham maiores possibilidades de serem aceitas por eles. As autoras concluíram que é importante inserir os alunos com deficiências no sistema regular de ensino em turma de alunos com idades similares, pois isso propicia participarem juntos da mesma atividade, favorecendo a interação e a aprendizagem mútua.

Com relação aos alunos com deficiência física, estes relatam interagir de forma satisfatória com seus colegas de classe, tanto no contexto socioeducacional como em outros espaços sociais (BALEOTTI, 2001). Na mesma direção, Braga, Rossi e Cole (2010) concluíram em seu estudo que a aprendizagem cooperativa, baseada na interação social, é uma ferramenta importante para o desenvolvimento da criança com paralisia cerebral e pode ser conduzida de maneira agradável, divertida e desafiadora.

Considerando o exposto, o objetivo deste estudo foi o de verificar a qualidade das relações interpessoais que se estabelecem entre a criança com paralisia cerebral e os demais colegas de classe durante atividades em grupo realizadas em sala de aula, nas quais se utiliza o brincar como recurso de ensino, bem como em situação de recreio.

\section{Método}

O presente estudo foi aprovado pelo Comitê de Ética na Pesquisa da Faculdade de Filosofia e Ciências, Unesp, campus de Marília, Protocolo No 468/2009.

Participaram deste estudo uma criança com diagnóstico clínico de paralisia cerebral (PC) do tipo quadriparesia espástica, do gênero masculino, com oito anos de idade, inserida no $3^{\circ}$ ano do ensino regular; a professora da classe na qual está inserida a criança com PC; e os colegas de classe. De acordo com relatos da professora, o aluno com PC estava alfabetizado, apresentava nível cognitivo compatível com a idade cronológica; acompanhava as atividades pedagógicas desenvolvidas em sala de aula; utilizava mais o membro superior esquerdo na realização das atividades escolares por apresentar menor dificuldade neste; comunicava-se verbalmente; e utilizava cadeira de rodas adaptada para locomoção, no entanto dependia de outra pessoa para o manuseio da mesma. Durante o recreio fez uso de andador infantojuvenil, tipo cadeira de rodas almofadada. Fez uso de alguns recursos da Tecnologia Assistiva, tais como letras e números imantados, mouse adaptado e mobiliário escolar adaptado. Devido à dificuldade no ato motor da escrita, realizava avaliaçóes oralmente. A classe era composta por 23 alunos, com idade variando entre oito e 10 anos, 15 do gênero feminino e oito do gênero masculino. Nenhum dos 22 colegas de classe apresentava qualquer tipo de deficiência. A professora era graduada em Pedagogia havia dois anos, com Habilitação em Administração e Supervisão Escolar, e atuava como professora de Ensino Fundamental havia seis anos. Com o aluno com PC tinha experiência de quatro meses de atuação. 
A coleta de dados foi realizada na escola por meio de entrevista semiestruturada com a professora, cujo roteiro era constituído por nove questóes abertas que, além dos dados de identificação, versavam sobre: participação e interesse da criança com PC em atividades lúdicas, atividades lúdicas proporcionadas no ambiente escolar e parceiros habituais da criança com PC durante a execução dessas atividades. Tal roteiro foi elaborado com base em um roteiro de entrevista proposto por Ferland (2006), o qual passou por adaptaçóes para atender aos objetivos deste estudo. Além da entrevista, foram realizadas filmagens da criança com PC em atividades lúdicas com seus colegas. O objetivo da filmagem foi o de registrar as interaçóes do aluno com PC para a avaliação da qualidade das interaçóes sociais que se efetivam entre ele e seus colegas de classe durante as brincadeiras.

Primeiramente, foi realizada entrevista com a professora. Após a análise de dados da entrevista, foi iniciado o procedimento de filmagem. Considerando que o foco principal de interesse se refere aos episódios interativos envolvendo o aluno com PC, decidiu-se chamálo de participante focal. Os demais alunos da classe foram participantes do estudo, embora não focais, na medida em que compuseram o contexto social do estudo e interagiam com o participante focal.

As filmagens durante o recreio foram realizadas nos mesmos dias das filmagens em sala de aula. Realizou-se um total de cinco sessóes de filmagem em cada ambiente. As filmagens em sala de aula tiveram duração de 20 a 30 minutos e as do recreio, aproximadamente de 15 minutos. Ocorreram no período de maio a agosto de 2010, realizadas quinzenalmente, objetivando fornecer informações que favorecessem a compreensão da natureza das relações sociais entre o aluno com PC e seus colegas de classe. Destaca-se que anteriormente à coleta de dados real, realizaram-se duas sessóes fictícias de filmagem para que os participantes se habituassem à presença da pesquisadora e da filmadora.

A análise de dados da entrevista foi iniciada pela transcrição da entrevista na íntegra, seguida da leitura de todo o material coletado, com a finalidade de analisar detalhadamente as falas fornecidas pela professora. Foram selecionadas as verbalizações referentes aos objetivos do estudo, ou seja, a unidade de análise foi composta por trechos de falas agrupadas por critério de semelhança que permeava cada tema do roteiro de entrevista.

Adotou-se para análise dos dados das filmagens um sistema de categorias criado por Aranha (1991) em seu trabalho acerca da identificação e caracterização das formas de relaçóes interpessoais de crianças pré-escolares com deficiência, integradas em escola regular. Tal sistema foi adaptado para atender aos objetivos e às peculiaridades deste estudo. Para a verificação da confiabilidade da classificação das dimensóes dos episódios interativos adotados, recorreu-se a análise feita por dois juízes comparando-a com a análise feita por uma das pesquisadoras deste estudo. Obteve-se entre o juiz 1 e a pesquisadora 100\%, e entre o juiz 2 e a pesquisadora o índice foi de 95\%, atestando a fidedignidade do sistema de categorias adotado. Após esse procedimento, foi iniciada a classificação de cada episódio interativo, tendo como parâmetro o sistema de categorias previamente desenvolvido e validado. Para cada sessão de filmagem, foram analisados todos os episódios interativos envolvendo a criança com PC e seus parceiros na brincadeira. 


\section{Resultados e Discussóes}

São apresentados inicialmente os resultados da filmagem que revelam as interaçóes efetivamente ocorridas. Em seguida, apresentam-se os resultados da entrevista buscando estabelecer relação entre o relato da professora e as interaçóes observadas na filmagem.

A Tabela 1 apresenta a distribuição do número de sessões de filmagem realizadas, o tempo total destas em sala de aula e recreio, a quantidade de episódios interativos envolvendo o aluno focal, bem como a classificação dos episódios quanto à duração do contato.

Embora tenham sido realizadas cinco sessões de filmagem em situação de recreio, a descrição da Tabela 1 refere-se apenas à primeira e à terceira sessões, pois nas demais não foram observados episódios de brincadeiras envolvendo a criança com PC e seus colegas. As atividades durante o recreio foram desenvolvidas na quadra. $\mathrm{Na}$ segunda sessão de filmagem, a quadra estava organizada para a festa junina da escola e, na quarta e quinta sessóes, o aluno com PC não tinha monitora para acompanhá-lo, permanecendo no refeitório conversando com algumas crianças, sem a ocorrência de atividade lúdica.

Ao lado da duração do contato, as informações relativas à pessoa que inicia o contato e o conteúdo deste podem permitir uma melhor compreensão da qualidade das relaçóes sociais que envolvem o aluno com deficiência. Assim, esses dados serão discutidos paralelamente aos dados apresentados na Tabela 1.

Tabela 1 - Caracterização das sessôes de filmagem e dos episódios interativos do aluno focal

\begin{tabular}{lcc}
\hline \multicolumn{2}{c}{ SALA DE AULA } & RECREIO \\
\hline Número de sessóes & 5 & 2 \\
Tempo total das sessões & $2 \mathrm{~h} .32 \mathrm{~min}$. & $31 \mathrm{~min}$. \\
No de episódios interativos & 117 & 15 \\
Caracterizaçáo do contato: & & 4 \\
- contato simples & 76 & 5 \\
- explosão de contato & 25 & 6 \\
- cadeia de contato & 16 & \\
\hline
\end{tabular}

Fonte: Elaboração própria

Para melhor elucidação dos episódios interativos, considerou-se conveniente relatar a forma como estava organizado o ambiente de sala de aula e a disposição do aluno com PC durante as atividades lúdicas. $\mathrm{O}$ aluno com $\mathrm{PC}$ era posicionado em cadeira adaptada em frente a uma mesa recortada em meia lua, o que facilitava o encaixe de tronco e posicionamento dos antebraços sobre a mesa. Sua carteira era a primeira da fileira ao lado da porta. Os alunos eram organizados em duplas ou em três alunos. Quando em duplas, as carteiras eram encostadas lado a lado, quando em trio, duas lado a lado e a terceira carteira encostada à frente, virada para as duas primeiras. A professora escolhia cada dia uma criança diferente para formar dupla ou trio com o aluno com PC. A escolha se dava mediante o questionamento relativo a quem gostaria de compor grupo com o mesmo. Várias crianças se manifestavam e a professora escolhia apenas uma ou duas, dependendo da organizaçáo da atividade do dia. Tanto a atitude da professora como a dos alunos evidenciavam-se acolhedoras, o que favorecia a interação social entre os envolvidos. 
Dos 117 episódios interativos envolvendo o aluno com PC em atividades de sala de aula, 76 foram classificados como contato simples, ou seja, episódios de dois únicos turnos, independente da duração, sendo um de cada sujeito. Os demais 41 foram de mais de dois turnos. Estes foram divididos em explosão de contato e cadeia de contato em função da duração.

Embora a maior parte dos episódios interativos seja de contatos simples, não dá para dizer que não houve interação significativa, considerando o conteúdo dos mesmos. Dos 76 contatos simples, 32 se caracterizaram por trocas iniciais, ou seja, trocas de olhares ou verbais de curta duração. Todos os episódios tinham caráter acolhedor, olhares e contatos físicos afetivos, sorrisos, dentre outras manifestações de acolhimento. Dados semelhantes são apontados na literatura acerca das atitudes em relação a alunos com deficiência física. Estes são mais bem aceitos comparativamente a alunos que têm problemas cognitivos, emocionais ou comportamentais, bem como em relação a alunos com deficiência auditiva, intelectual ou visual (ARTIOLI, 1999; BALBONI; PEDRABISSI, 2000; JOBE; RUST; BRISSIE, 1996).

É oportuno destacar que oito dos contatos simples tiveram como conteúdo solicitação de objeto. $\mathrm{O}$ aluno com PC tem em sua mesa um porta-lápis que contém lápis adaptados, os quais despertam a curiosidade dos demais alunos e vários se dirigem à carteira dele para pedir um lápis emprestado. Neste caso, o uso do recurso diferenciado, de certa forma, tem favorecido a aproximação dos demais alunos. Para Silva (2010), o recurso pedagógico não deve ser adaptado somente às necessidades do aluno, mas deve ser adaptado com o intuito de proporcionar aprendizagem e interação do aluno com os colegas de classe.

De fato, os recursos adaptados para o aluno com PC deste estudo têm o intuito de favorecer o acesso ao currículo e a participação nas atividades desenvolvidas no contexto de sala de aula. A interação na atividade ocorre a partir do momento em que lhe são proporcionadas condições materiais para isso, o que favorece também a interação social. É importante que o professor fique atento às situaçóes de movimentação e curiosidade dos demais alunos no que concerne aos recursos adaptados. Tais situações podem ser disruptivas em relação à ação pedagógica em andamento, e também o contato não deve ser favorecido apenas pelo interesse que objetos adaptados despertam nos demais alunos. A aproximação em função do recurso adaptado não é sinônimo de interação social e não significa que o aluno com deficiência esteja sendo bem acolhido pelos demais colegas.

No presente estudo, evidenciaram-se relações de acolhimento em outras situações. No processo inclusivo, é preciso estar atento para as relaçóes que se estabelecem espontaneamente entre o aluno com deficiência e os demais colegas. A inclusão refere-se também à interação entre as pessoas, e isso é muito mais complexo do que garantir a matrícula na escola comum ou adaptaçóes do meio.

Vinte e cinco episódios interativos foram explosão de contato, ou seja, episódios com duração máxima de 10 segundos e com mais de dois turnos. Considera-se que esses episódios também são pouco representativos em termos de duração de contato. Porém, com relação ao conteúdo, observou-se acolhimento: 18 foram auxílio, episódio em que alguém se dirige ao outro, espontaneamente para lhe prestar assistência em relação à execução da tarefa. Esses episódios foram na sua totalidade iniciados por colegas do aluno com PC auxiliando-o na realização da atividade. Outros sete episódios foram caracterizados por brincadeiras espontâneas, 
episódios em que há comportamento de criação de brincadeiras da criança com PC em relação aos parceiros presentes na brincadeira e/ou destes em relação à criança com PC. Em um desses episódios, uma aluna enche a bexiga e solta o ar no rosto do aluno com PC que se diverte com a brincadeira da colega.

Dezesseis foram episódios de cadeia de contato, episódios interativos complexos, com mais de 10 segundos de duração e com mais de dois turnos. Tiveram como conteúdo auxílio ou solicitação de ação, ocasião em que as crianças incentivavam o aluno com PC a realizar a atividade lúdica. $\mathrm{O}$ incentivo era seguido de conversas que ocorriam durante as atividades em grupo.

Com relação à interação durante o recreio, conforme mencionado na Tabela 1, ocorreram 15 episódios interativos, sendo quatro caracterizados como contatos simples, cinco como explosóes de contato e seis como cadeias de contato. Cabe salientar que diferentes brincadeiras são realizadas, geralmente com as crianças brincando em pequenos grupos espalhados pela quadra. Nos dois dias de observação, a brincadeira realizada entre a criança com PC e seus colegas foi o pega-pega. Em um desses episódios, três crianças solicitavam da criança com PC que as pegasse, esta corria atrás delas usando o andador. Eram várias crianças brincando juntas e os conteúdos eram trocas iniciais, ou seja, olhares, sorrisos, verbalizaçóes de curta duração, como comumente acontece nesse tipo de brincadeira.

Observa-se que ocorreram interaçóes envolvendo o aluno com PC tanto em atividades em sala de aula como durante o recreio. Tais interaçóes caracterizam-se por trocas interativas efetivas tendo em vista os conteúdos dos contatos estabelecidos.

Apresentam-se, na sequência, os dados obtidos na entrevista, buscando, na medida do possível, estabelecer aproximação entre esses dados e os da filmagem. Os resultados da entrevista se apresentam em eixos temáticos.

$\mathrm{O}$ primeiro tema investigado tratou da percepção da professora quanto à participação da criança com PC em atividades lúdicas e à manifestação de interesse desta em participar de tais atividades.

De acordo com a professora, a criança com PC demonstra interesse e participa de todas as atividades lúdicas propostas em sala de aula, como se evidencia na sua fala: "Participa de todas. Participa mais que alguns outros alunos. Ele brinca normal, é bem participativo". Percebe-se na fala da professora que ela parece olhar para as habilidades do aluno com PC e ainda faz comentários positivos sobre ele ao compará-lo com os demais colegas de classe. $\mathrm{O}$ interesse pelo brincar pode estar relacionado ao fato de as brincadeiras serem incentivadas pela professora, o que provavelmente estimula o compartilhar e o envolvimento nas brincadeiras entre as crianças da classe.

Nas verbalizações gravadas nas filmagens, constatou-se que a professora propunha algumas atividades lúdicas em duplas e outras em grupos de três crianças. Durante essas atividades, o aluno com PC demonstrava interesse e sempre estava atento aos comandos dados pela professora, no entanto a sua participação efetiva na realização das atividades em alguns momentos não foi evidenciada. Parece que a restrição na participação se deveu ao fato de algumas atividades não estarem adequadas às condiçốes motoras do aluno com $\mathrm{PC}$, bem

${ }^{5}$ Relato da professora 
como ao fato de os colegas não terem paciência em esperar que o aluno com PC concluísse a atividade, realizando-a por ele. $\mathrm{O}$ Quadro 1 exemplifica as atividades dadas pela professora e a participação do aluno com PC.

\begin{tabular}{|l|l|l|}
\hline Tomadas focais & Atividade dada pela professora & Atividade do aluno com PC \\
\hline $1^{\text {a }}$ sessão & Dominó relacionado à atividade de matemática & Realiza atividade com auxílio. \\
$2^{\text {a }}$ sessão & Confecção de foguete - atividade de ciências & Não faz a atividade. \\
$3^{\text {a }}$ sessão & Colagem de bandeira & Realiza atividade com auxílio. \\
$4^{\text {a }}$ sessão & Pintura e combinação lógica da figura humana & Realiza atividade com auxílio. \\
$5^{\text {a }}$ sessão & Pintura e quebra-cabeça & Realiza atividade com auxílio. \\
\hline
\end{tabular}

Quadro 1 - Atividades executadas pela professora e a participaçáo do aluno com PC

Constata-se no quadro acima que o aluno com PC realizou a maioria das atividades com auxílio. Observou-se que o auxílio dos colegas consistia principalmente no aspecto motor, devido à dificuldade de o aluno manipular as peças do jogo e os objetos utilizados para as demais atividades. Com relação ao jogo de dominó, o aluno com PC participava respondendo as questóes que o colega fazia, por exemplo, com relação ao valor numérico da peça de dominó. Nas demais atividades que exigiam coordenação motora fina para colagem e pintura, notouse que a quantidade de auxílio foi maior. $\mathrm{O}$ colega ajudava o aluno com PC a relacionar a cor a ser pintada com o desenho do jogo, posicionava e segurava a folha para que o mesmo pudesse realizar a pintura. Aparentemente, isso se deveu ao fato de o aluno com PC demorar demasiadamente para iniciar as atividades, pois estas não eram adequadas às suas condiçóes.

A literatura tem apontado que, de um modo geral, os professores enfatizam que não se sentem preparados para lidar com o aluno com sequela de paralisia cerebral (GOMES; BARBOSA, 2006). A maioria dos professores não possui conhecimento específico sobre a paralisia cerebral e desconhece as implicaçóes dessa patologia para o processo de ensino e aprendizagem do aluno com deficiência física (MELLO; MARTINS, 2004).

Se as atividades fossem adaptadas às necessidades do aluno com PC, certamente a participação seria melhor. A parceria entre profissionais da saúde e da educação pode ser importante para o processo de escolarização do aluno com paralisia cerebral. Os resultados deste estudo aliados aos dados da literatura trazem contribuiçóes relevantes para a área da saúde, especialmente para a Terapia Ocupacional. Terapeutas ocupacionais constituem-se excelentes parceiros para os professores, pois têm em sua formação conhecimentos específicos que lhes permitem atuar nos aspectos ergonômicos do ambiente escolar, a fim de adequar o entorno por meio de adaptaçóes individuais, físicas e/ou dos materiais utilizados, a partir da constataçáo da melhor maneira de o aluno responder aos desafios inerentes ao contexto educacional (BALEOTTI, 2006; BERSCH, 2006; BARTALOTTI; CARLO, 2001).

Embora a inadequação da atividade tenha favorecido a cooperação entre os colegas, para que ocorra o ensino mútuo com caráter acolhedor e solidário, é necessária a provisão de atividades adequadas que favoreçam a participação e autonomia do aluno com deficiência no ambiente escolar. 
Com base na análise da interação e da participação do aluno com PC nas atividades lúdicas, tem-se nítida visão de que muitas das dificuldades manifestadas por ele poderiam ter sido amenizadas pela ação conjunta entre a professora e o terapeuta ocupacional. Este, por meio de conhecimentos relativos à análise e aplicação da atividade, possui competência profissional para auxiliar os professores na adaptação das atividades escolares e dos recursos utilizados para a realização das mesmas.

A análise de atividades é uma forma de raciocínio científico utilizada por terapeutas ocupacionais para compreender as atividades, as áreas de desempenho, os componentes de desempenho e os contextos de desempenho nos quais o comportamento ocupacional do indivíduo se manifesta (CREPEAU, 2002).

Açóes junto à professora não constituíam parte dos objetivos deste estudo, mas por considerar a relevância dos dados para possíveis contribuiçóes da terapia ocupacional no contexto escolar, considerou-se oportuna e necessária a realização de devolutiva à professora quanto às possibilidades de adaptaçóes das atividades lúdicas observadas. Tal devolutiva foi dada por meio de conversa informal com a professora, cujo foco foi a discussão e apresentação de soluçóes para os problemas percebidos. Fornecer informaçóes sobre possíveis alternativas em termos de ensino e estratégias voltadas a facilitar a participação do aluno com PC é extremamente relevante para concretizar a educação inclusiva.

$\mathrm{O}$ segundo tema investigado na entrevista tratou de questóes relativas às atividades lúdicas proporcionadas no contexto escolar. A professora relatou que procura proporcionar estas atividades para toda a classe, enfatizando a importância do brincar para o processo de ensino e aprendizagem de todos os alunos. Assim ela se expressou: "Sempre trabalho com o lúdico, até em texto, quando é texto fazemos teatro, em artes, em matemática, com o objetivo de ensinar brincando ${ }^{6 ”}$.

Conforme Quadro 1, na análise das sessóes de filmagem, percebeu-se que a professora proporcionou atividades lúdicas em sala de aula relacionando-as aos aspectos pedagógicos, o que denota a importância que ela parece atribuir ao lúdico para o processo de ensino e aprendizagem. O estudo de Martins, Vieira e Oliveira (2006) evidenciou que a brincadeira foi considerada importante para o desenvolvimento social e contribuiu para o convívio social das crianças, segundo os professores da Educação Infantil.

O terceiro tema tratou da percepção da professora quanto aos parceiros habituais da criança com PC durante as atividades lúdicas. A professora enfatizou que todos os alunos da classe brincavam e interagiam com a criança com PC, mostrando uma relação satisfatória.

O relato apresenta consonância com os dados coletados nas filmagens. Durante a realização de atividades lúdicas, diversas crianças participavam junto com o aluno com PC. A maioria dos alunos parecia demonstrar desejo de brincar e ajudá-lo na realização das atividades. Diante dessa situação, a professora selecionava aleatoriamente os alunos que fariam dupla ou trios com a criança com PC quando alguma atividade lúdica era realizada em sala de aula. Resultados semelhantes foram encontrados por Yazlle, Amorim e Rossetti-Ferreira (2004). O estudo desses autores, com pais, professores e profissionais da saúde de quatro crianças com PC

${ }^{6}$ Relato da professora 
que frequentavam a pré-escola, evidenciou que os colegas de classes de pré-escola mostravamse interessadas e disponíveis para a convivência com as crianças com PC, estabelecendo uma relação de ajuda e cuidado.

Ressalta-se que o presente estudo evidenciou atitudes de acolhimento dos demais colegas em relação ao aluno com PC. Não foi evidenciada em nenhum momento atitude de discriminação ou desrespeito. Esse dado é extremamente relevante no contexto da educação inclusiva. Baleotti (2006) alerta para o fato de que a inclusão refere-se também à interação entre as pessoas e isso é muito mais complexo do que garantir a matrícula na escola comum. A inserção de alunos com deficiência no ensino comum, se determinada apenas por imposição legal, não assegura que serão bem acolhidos pelo professor e colegas da classe nem lhes garante ensino de qualidade mediante adequaçóes que atendam às suas particularidades e necessidades especiais. A segregação ou a inclusão pode depender, em grande parte, do tipo de relação estabelecida entre o aluno com deficiência, o professor e seus pares não deficientes.

Cabe destacar que a participação do aluno com PC nas atividades ficou prejudicada em função da lacuna presente entre as condiçóes do aluno e as demandas da atividade. É importante esse destaque considerando a política da educação inclusiva que prevê adaptaçóes em diversos âmbitos da escola, inclusive nas atividades e materiais utilizados em sala de aula a fim de favorecer o acesso ao currículo para todos os alunos, independente de suas necessidades físicas, sensoriais ou intelectuais.

\section{Conclusốes}

Neste estudo, buscou-se compreender como se efetiva a interação entre uma criança com PC e seus colegas de classe, pois essa interação, tanto positiva quanto negativa, pode ser bastante significativa na vida dessa criança. As relaçóes sociais que uma criança com PC constrói na sua classe podem ter efeitos expressivos sobre a sua participação nas demais atividades da escola.

Por ser estudo de um único caso, tomou-se o cuidado de selecionar uma criança com grave comprometimento funcional do ponto de vista motor. Os autores ponderam que crianças com PC, com características motoras semelhantes às do presente caso, podem encontrar-se em situação muito especial no contexto educacional inclusivo. Essa situação especial se deve à necessidade evidente de adequação da estrutura física e dos materiais escolares que possibilitem a participação efetiva nas atividades desenvolvidas na sala de aula. Pretendeu-se, adicionalmente, levantar algumas evidencias para discutir quanto o comprometimento motor associado à falta ou à presença de mobiliário adequado ou brinquedos adaptados influencia o processo de interação social por meio do brincar entre a criança com PC e seus colegas de classe.

Apesar de os jogos utilizados e as atividades selecionadas nos dias de observação náo atenderem às necessidades motoras do aluno, constatou-se, por meio dos relatos da professora e da observação, que as interaçóes que se efetivavam envolvendo o aluno com PC foram marcadas por clima de acolhimento. As condiçóes motoras do aluno não interferiram negativamente nas relaçóes sociais estabelecidas entre ele e os colegas de classe. Provavelmente, o ambiente acolhedor observado está repercutindo positivamente no processo de socialização, de desenvolvimento e de aprendizagem de todas as crianças. Circunstâncias dessa natureza 
podem prover oportunidade para aguçar a tolerância às diferenças e o senso de solidariedade em todas as crianças que participam da situaçáo.

A inadequação presente nas demandas dos recursos pedagógicos utilizados pelo aluno com PC ficou evidente. Das cinco atividades observadas, uma o aluno não realizou e as demais foram realizadas com auxílio dos colegas. $\mathrm{O}$ auxílio prestado pelos colegas possibilitou, mesmo que minimamente, a participação do aluno com $\mathrm{PC}$ em atividades. Os resultados obtidos foram positivos devido à ação da professora no sentido de favorecer tanto as interaçóes como a intenção no estabelecimento de estratégias pedagógicas que favorecessem o processo de ensino e aprendizagem de todos os alunos.

Há a necessidade de que os professores estruturem situaçóes que estimulam e favorecem a cooperação entre os envolvidos e permitem o avanço no processo de amadurecimento e a aquisição de conhecimentos por parte de todos os alunos, inclusive do aluno com deficiência. $\mathrm{O}$ trabalho didático-pedagógico deve ocorrer no sentido de criar um ambiente interacional e educativo acolhedor que favorece a consecução de metas que qualquer educação de qualidade propóe.

É desejável a continuidade desta investigação mediante a ampliação do número de participantes, com quadros clínicos variáveis, inclusive com a inserção de crianças com PC com comorbidades. Somente assim será possível verificar se o resultado encontrado no presente estudo representa uma tendência comum do que ocorre em classes das quais participa um aluno com limitaçóes motoras acentuadas.

\section{REFERÊNCIAS}

ANDRETTO, Y. T. T. Os impactos iniciais da inclusão de crianças deficientes no ensino regular: um estudo sobre a inclusão de criança com paralisia cerebral. 2001. 118 f. Dissertação (Mestrado em Distúrbio de Desenvolvimento) - Universidade Presbiteriana Mackenzie, Sáo Paulo, 2001.

ANHÃO, P. P. G.; PFEIFER, L. I.; SANTOS, G. L. Interação social de crianças com síndrome de down na educação infantil. Revista Brasileira de Educação Especial, Marília, v.16, n.1, p.31-46, 2010.

ARANHA, M.S.F. A interação social e o desenvolvimento de relaçôes interpessoais do deficiente em ambiente integrado. 1991. 145 f. Tese (Doutorado em Psicologia Experimental) - Instituto de Psicologia. Universidade de São Paulo, São Paulo, 1991.

ARAÚJO, A.E.; GALVÃO, C. Desordens motoras. In: CAVALCANTI, A.; GALVÃO, C. (Org.). Terapia ocupacional: fundamentação e prática. Rio de Janeiro: Guanabara Koogan, 2007. p. 328-337.

ARTIOLI, A. L. A Integração do aluno deficiente na classe comum: o ponto de vista do professor. 1999. 219 f. Dissertação (Mestrado em Educação) - Faculdade de Filosofia e Ciências, Universidade Estadual Paulista, Marília, 1999.

BALBONI, G.; PEDRABISSI, L. Attitudes of italian teachers and parents toward school inclusion of students with mental retardation: the role of experience. Education and Training in Mental Retardation and Developmental Disabilities, Italy, v. 35, n. 2, p. 148-159, 2000.

BALEOTTI, L. R. Experiência escolar do aluno com deficiência física no ensino comum: o ponto de vista do aluno. 2001. 78 f. Dissertação (Mestrado em Educação) - Faculdade de Filosofia e Ciências, Universidade Estadual Paulista, Marília, 2001. 
- Um estudo do ambiente educacional inclusivo: descrição das atitudes sociais em relação à inclusão e das relaçôes interpessoais. 2006. 183 f. Tese (Doutorado em Educação) - Faculdade de Filosofia e Ciências, Universidade Estadual Paulista, Marília, 2006.

BARTALOTTI, C.C.; DE CARLO, M.M.R.P. Terapia Ocupacional e os processos socioeducacionais. In: BARTALOTTI, C. C.; DE CARLO, M. M. R. P. (Org.). Terapia Ocupacional no Brasil: fundamentos e perspectivas. São Paulo: Plexus Editora, 2001. p. 99-116.

BERSCH, R. Introdução à tecnologia assistiva, 2006. Disponível em: <http://www.assistiva.com.br/ Introducao\%20TA\%20Rita\%20Bersch.pdf >. Acesso em: 5 mar. 2008.

BRAGA, L.W.; ROSSI, L.; COLE, M. Criar uma ideocultura para promover o desenvolvimento de crianças com paralisia cerebral. Educação e Pesquisa, São Paulo, v. 36, n. especial, p. 133-143, 2010.

CORDAZZO, S. T. D.; VIEIRA, M. L. As brincadeiras e suas implicaçôes nos processos de aprendizagem e desenvolvimento. Estudo e Pesquisa em Psicologia, Rio de Janeiro, ano 7, n. 1, p. 89101, 2007.

CREPEAU, E. B. Análise de Atividades: Uma Forma de Refletir sobre o Desempenho Ocupacional. In: NEISTADT, M. E.; CREPEAU, E.B. (Org.) Willard \& Spackman: terapia ocupacional. 9.ed. Rio de Janeiro: Guanabara Koogan, 2002, p.121-133.

FERLAND, F. $O$ modelo lúdico: o brincar, a criança com deficiência física e a terapia ocupacional. 3. ed. São Paulo: Roca, 2006.

GOMES, C.; BARBOSA, A. J. G. Inclusão escolar do portador de paralisia cerebral: atitude de professores do ensino fundamental. Revista Brasileira de educação especial, Marília, v. 2, n. 1, p. 85-100, 2006.

JOBE, D.; RUST, J.O.; BRISSIE, J. Teacher attitudes toward inclusion of students with disabilities into regular classrooms. Education, v. 117, n. 1, p. 148-154, 1996.

JULIANI, A. L. M.; PAINI, L. D. A importância da ludicidade na prática pedagógica: em foco o atendimento às diferenças, [2008]. Disponível em: <http://www.diaadiaeducacao.pr.gov.br/portals/ pde/arquivos/2113-8.pdf>. Acesso em: 25 out. 2010.

LOPES, L. W. R.; MAGALHÁES, C. M. C.; MAURO, P. I. Interaçóes entre pré escolares: possibilidades de análises. Psicologia: ciência e profissão, Brasília, v. 23, n. 4, p. 88-97, 2003.

MARTINS, G. D. F.; VIEIRA, M. L.; OLIVEIRA, A. M. F. Concepçôes de professores sobre brincadeira e sua relação com o desenvolvimento na educação infantil. Interação em Psicologia, Curitiba, v. 10, n. 2, p. 273-285, 2006.

MELLO, F. R. L. V.; MARTINS, L. A. R. O que pensa a comunidade escolar sobre o aluno com paralisia cerebral. Revista Brasileira de Educaçâo Especial, Marília, v. 10, n. 1, p. 75-92, 2004.

MILLER, G.; CLARCK, D. G. Paralisias cerebrais: causas, consequências e condutas. São Paulo: Manole, 2002.

PIMENTEL, S. C. O especial dos jogos e brincadeiras no atendimento às diferenças. Revista FAEEBA: Educação e Contemporaneidade, Salvador, v. 15, n. 25, p. 147-156, 2006.

SILVA, M. O. Protocolo para prescrição ou adaptação de recursos pedagógicos para alunos com paralisia cerebral. 2010. 195f. Dissertação (Mestrado em Educação) - Faculdade de Filosofia e Ciências, Universidade Estadual Paulista, Marília, 2010. 
SILVA, L. F.; CABRAL, I. E.; CHRISTOFFEL, M. M. O brincar na vida do escolar com câncer em tratamento ambulatorial: possibilidades para o desenvolvimento. Revista brasileira de crescimento $e$ desenvolvimento humano, São Paulo, v.18, n.3, p. 275-287, 2008.

TEIXEIRA, F. C.; KUBO, O. M. Características das interações entre alunos com Síndrome de Down e seus colegas de turma no sistema regular de ensino. Revista Brasileira de Educação Especial, Marília, v.14, n.1, p. 75-92, 2008.

YAZLLE, C. H. D.; AMORIM, K. S.; ROSSETTI-FERREIRA, M. C. A rede de significações na investigação do processo de inclusão de crianças portadoras de paralisia cerebral em pré escolas. In: ROSSETTI-FERREIRA, M. et al. Rede de significaçóes e o estudo do desenvolvimento humano. Porto Alegre: Artmed, 2004.

Recebido em: 16/09/2011

Reformulado em: 15/05/2012

Aprovado em: 27/09/2012 